\title{
Patterns of recurrence in adenocarcinoma of the esophagogastric junction: a retrospective study
}

\author{
Haitao X ${ }^{1} \mathbb{D}$, Lianguo Zhang ${ }^{1}$, Jing Miao ${ }^{2}$, Shuai Liu' ${ }^{1}$, Hongjian Liu' ${ }^{1}$ Teng Jia ${ }^{1}$ and Qingguang Zhang ${ }^{1 *}$
}

\begin{abstract}
Background: The prognosis of adenocarcinoma of the esophagogastric junction (AEG) is poor. Understanding the postoperative recurrence pattern of AEG is helpful to verify the effectiveness of treatment and optimize subsequent treatment, so as to improve prognosis.

Methods: This single-center retrospective study included patients with stage III AEG who underwent surgical treatment between January 2009 and December 2016. According to the different postoperative treatment arm, patients were divided into surgery and surgery plus chemotherapy groups. Recurrence-free survival was used as the outcome to compare the recurrence site and pattern between the groups.

Results: In total, were 306 patients enrolled, 123 in the surgery group and 183 in the surgery plus chemotherapy group. During follow-up (median 17.1 months) of 24 months after surgery, $62.0 \%$ of patients had tumor recurrence. The overall recurrence rates in the surgery and surgery plus chemotherapy groups were $86.9 \%$ and $77.0 \%$, respectively. The recurrence patterns of both groups were mainly distant metastasis. Postoperative chemotherapy reduced the incidence of hematogenous dissemination from 51.2 to $42.0 \%$. Multivariate Cox analysis showed that the pN stage increased the risk of recurrence, while surgery plus chemotherapy reduced the risk.

Conclusions: Patients with AEG have a risk of hematogenous dissemination after surgery. Postoperative treatment arm and $\mathrm{pN}$ stage were independent risk factors in patients with AEG. Surgery plus chemotherapy can improve recurrence-free survival and reduce distant metastasis, but they do not have a beneficial role in controlling local recurrence.
\end{abstract}

Keywords: Adenocarcinoma of the esophagogastric junction, Recurrence, Surgery, Chemotherapy, prognosis

\section{Background}

Adenocarcinoma of the esophagogastric junction (AEG) is also known as cardiac cancer in China, and its incidence is increasing in Asian countries including China [1]. Siewert et al. [2] proposed a classification system for AEG. Siewert II and III are the main types in China [3], which differs from the Western countries. Although

\footnotetext{
* Correspondence: drzhangqingg@126.com

1 Department of Thoracic Surgery, Binzhou Medical University Hospital, No. 661 Huanghe 2nd Road, Binzhou 256603, Shandong, People's Republic of China

Full list of author information is available at the end of the article
}

consensus has been reached in various aspects such as tumor nomenclature, surgical approach, digestive tract reconstruction, and scope of lymph node dissection, there are still many controversies because of its special anatomical location $[4,5]$.

Surgical resection is the first treatment of choice for AEG. However, clinical trials of AEG are mostly conducted in patients with esophageal cancer [6] or gastric cancer $[7,8]$, and the recurrence pattern of AEG after surgery is rarely reported. AEG has a poor prognosis $[9$, 10]. Understanding the recurrence pattern of AEG is

(c) The Author(s). 2020 Open Access This article is licensed under a Creative Commons Attribution 4.0 International License, which permits use, sharing, adaptation, distribution and reproduction in any medium or format, as long as you give appropriate credit to the original author(s) and the source, provide a link to the Creative Commons licence, and indicate if changes were made. The images or other third party material in this article are included in the article's Creative Commons. licence, unless indicated otherwise in a credit line to the material. If material is not included in the article's Creative Commons licence and your intended use is not permitted by statutory regulation or exceeds the permitted use, you will need to obtain permission directly from the copyright holder. To view a copy of this licence, visit http://creativecommons.org/licenses/by/4.0/ The Creative Commons Public Domain Dedication waiver (http://creativecommons.org/publicdomain/zero/1.0/) applies to the data made available in this article, unless otherwise stated in a credit line to the data. 
helpful to verify the effectiveness of treatment and improve prognosis by optimizing treatment strategies.

Therefore, in this study, we retrospectively analyzed the recurrence sites and patterns of AEG in patients receiving surgery alone and surgery plus chemotherapy, as well as the related factors affecting recurrence-free survival (RFS).

\section{Methods}

\section{Patients}

We retrospectively analyzed patients with AEG who underwent surgery in the Binzhou Medical University Hospital between January 2009 and December 2016. The tumor location was classified according to the Siewert classification system based on the contrast radiography, endoscopy, computed tomography, intraoperative findings, and histological examination. Inclusion criteria were as follows: (1) no residual tumor under microscope; (2) patients receiving surgical treatment alone; (3) patients receiving chemotherapy after surgery, but not radiotherapy; (4) patients receiving no fewer than four cycles of adjuvant chemotherapy after surgery; (5) patients with Siewert type II tumor according to the 7th edition of American Joint Committee on Cancer staging [11], and postoperative pathology stage III; (6) clinical and follow-up data are complete; and (7) no history or coexistence of other malignant tumors. The patients were divided into two groups: surgery group and surgery plus chemotherapy group. This study was approved by the Ethics Committee of the Binzhou Medical University Hospital (No. 2018-WST-2017WS555).

\section{Surgery and chemotherapy}

The choice of surgical approach depended on tumor size, mode of digestive tract reconstruction, experience of surgeons, and general condition of the patients. The surgical approaches included transthoracic partial esophagectomy plus partial gastrectomy and regional lymph node dissection, and transabdominal total gastrectomy plus partial esophagectomy and regional lymph node dissection. Digestive tract reconstruction involved the tubular stomach or jejunum. Patients received the first chemotherapy within 4-6weeks after surgery. The chemotherapy regimen was intravenous infusion of 40 $\mathrm{mg} / \mathrm{m}^{2}$ cisplatin for 3 consecutive days and $500 \mathrm{mg} / \mathrm{m}^{2}$ fluorouracil for 5 consecutive days for four cycles with an interval of 3-4 weeks [12].

\section{Tumor recurrence}

Recurrence included local recurrence and distant metastasis. Locoregional recurrence was defined as recurrence of primary tumors or in local lymph nodes. Local lymph nodes included lymph nodes around the celiac axis and in the lower mediastinum. Distant metastasis was defined as hematogenous dissemination (including liver, lung, bone, and other parenchymal organs), pleural metastasis, peritoneal metastasis, and distant lymph node metastasis (including nonregional lymph nodes such as neck, axilla, and subclavian). Local recurrence and distant metastasis were judged by chest or abdominal computed tomography, endoscopy, and cytological or histological examination.

\section{Follow-up}

Clinical data were collected through the electronic medical record management system of Binzhou Medical University Hospital. Regular telephone follow-up, combined with outpatient visit data collection was carried out. The last follow-up date was December 30, 2018. The outcome was RFS, which was defined as the time from surgery to recurrence or death. The patient's age was calculated from the time of operation.

\section{Statistical analysis}

Classified variables were analyzed by the chi-square test and continuous variables were tested by $t$ test. The survival curve was drawn by the Kaplan-Meier method. Log rank analysis was used to test the differences in the survival curves. The hazard ratio (HR) and 95\% confidence interval (CI) of the survival curves were calculated using the Cox proportional risk model. Univariate and multivariate Cox regression analyses were used to analyze the prognostic factors. The backward-step method was used to optimize the multivariate model. Univariate Cox regression model was also used to analyze the difference in recurrence sites in each treatment group. Statistical analyses were performed using SPSS for Windows version 22.0 (IBM SPSS, Chicago, IL, USA) and STATA for Windows version 15.0 (StataCorp LP, College Station, TX, USA). $P<0.05$ was considered statistically significant, and all tests were two-sided.

\section{Results \\ Patients}

From January 2009 to December 2016, 530 patients with stage III AEG underwent surgery in the Binzhou Medical University Hospital. We enrolled 306 patients, 123 in the surgery group and 183 in the surgery plus chemotherapy group according to the inclusion criteria. Among the 306 analyzed patients, the median age was 63 years. There were 110 men and 13 women in the surgery group, with a median age of 65 years (range $42-79$ years). There were 156 men and 27 women in the surgery plus chemotherapy group, with a median age of 62 years (28-81 years). There were differences in age distribution between the two groups. There was no difference in the baseline distribution of gender, tumor size, cT stage, cN stage, $\mathrm{pT}$ stage, $\mathrm{pN}$ stage, pTNM stage, 
histological type, and number of resected lymph nodes between the two groups (Table 1).

\section{Patterns of recurrence}

The median follow-up time was 17.1 months, and median RFS was 17.2 months (12.9 months in the surgery group and 19.6 months in the surgery plus chemotherapy group). Recurrence was found in 248 patients $(81.0 \%), 107(86.9 \%)$ in the surgery group and 141 $(77.0 \%)$ in the surgery plus chemotherapy group, respectively. Within 730 days after surgery, the recurrence rate was $62.0 \%(190 / 306)$. The main recurrence pattern in both groups was distant metastasis. In the surgery group, 29 patients (23.5\%) had local recurrence and 85 patients $(69.1 \%)$ had distant metastasis. In the surgery plus chemotherapy group, 40 patients (21.8\%) had local recurrence and 110 patients (60.1\%) had distant metastasis. In both groups, seven and nine patients had local recurrence and distant metastasis at the same time. Figures 1 and 2 show the differences in RFS and

Table 1 Baseline patients characteristics

\begin{tabular}{|c|c|c|c|}
\hline Characteristics & $S(n=123), n(\%)$ & $S+C T(n=183), n(\%)$ & $P$ value \\
\hline Age, years & & & $<0.001$ \\
\hline Median & 65 & 62 & \\
\hline Range & $42-79$ & $28-81$ & \\
\hline Sex & & & 0.287 \\
\hline Male & $110(89.4)$ & $156(85.2)$ & \\
\hline Female & $13(10.6)$ & $27(14.8)$ & \\
\hline Tumor length, cm & & & 0.084 \\
\hline Median & 5 & 5.5 & \\
\hline Range & $1.8-10.0$ & $1.6-12.0$ & \\
\hline pT stage/cT stage & & & 0.162 \\
\hline $\mathrm{T} 2$ & $3(2.4)$ & $3(1.6)$ & \\
\hline T3 & $82(66.7)$ & $104(56.8)$ & \\
\hline T4a & $38(30.9)$ & $76(41.5)$ & \\
\hline pN stage & & & 0.932 \\
\hline NO & $12(9.8)$ & $16(8.7)$ & \\
\hline N1 & $23(18.7)$ & $38(20.8)$ & \\
\hline N2 & 39 (31.7) & $61(33.3)$ & \\
\hline N3 & 49 (39.8) & $68(37.2)$ & \\
\hline pTNM stage & & & 0.617 \\
\hline Illa & $32(26.0)$ & $44(24.0)$ & \\
\hline IIlb & $32(26.0)$ & $41(22.4)$ & \\
\hline IIlc & $59(48.0)$ & $98(53.6)$ & \\
\hline Histology & & & 0.770 \\
\hline Well-differentiated AC & $6(4.9)$ & $10(5.4)$ & \\
\hline Moderately differentiated AC & $35(28.5)$ & $53(29.0)$ & \\
\hline Poorly differentiated AC & $57(46.3)$ & $75(41.0)$ & \\
\hline Mucinous AC & $25(20.3)$ & $45(24.6)$ & \\
\hline Method of resection & & & 0.053 \\
\hline TTE & $70(56.9)$ & $124(66.8)$ & \\
\hline TAE & $53(43.1)$ & $59(32.2)$ & \\
\hline Number of resected lymph nodes & & & 0.278 \\
\hline$($ mean $\pm \mathrm{SD})$ & $19.21 \pm 8.734$ & $20.25 \pm 7.848$ & \\
\hline cN stage & & & 0.917 \\
\hline No & $18(14.6)$ & $26(14.2)$ & \\
\hline N1 & $105(85.4)$ & $157(85.8)$ & \\
\hline
\end{tabular}




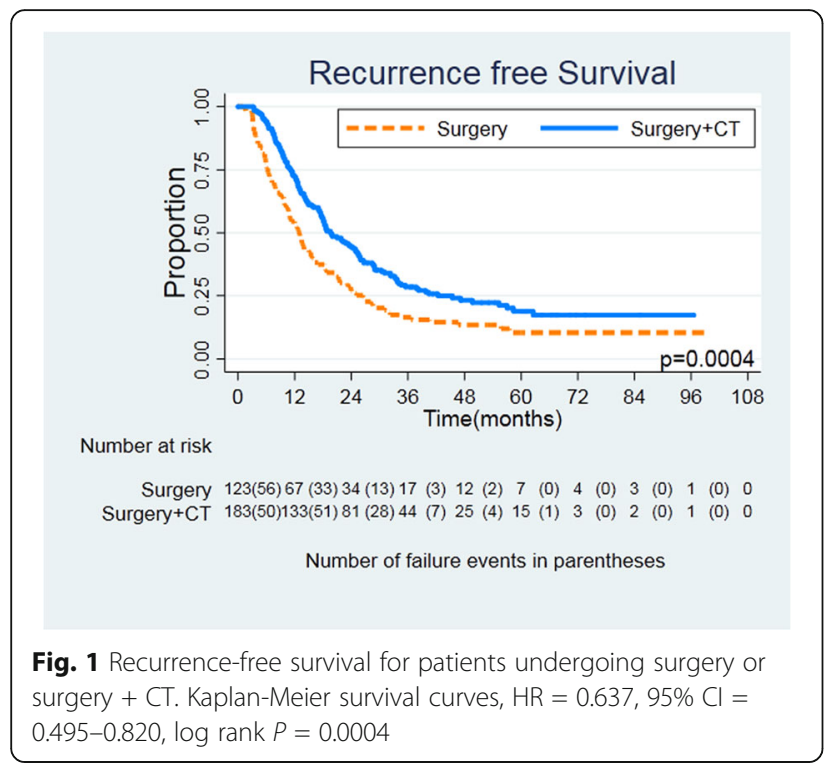

distant metastasis-free survival $(\mathrm{HR}=0.0 .637,95 \% \mathrm{CI}=$ 0.495-0.820, $\log \operatorname{rank} P=0.0004 ; \mathrm{HR}=0.632,95 \% \mathrm{CI}=$ $0.476-0.839, \log \operatorname{rank} P=0.0014)$. There was no difference in locoregional RFS between the two groups $(\mathrm{HR}=0.648$, $95 \% \mathrm{CI}=0.401-1.047, \log \operatorname{rank} P=0.074$ ) (Fig. 3 ).

\section{Site of tumor recurrence}

Tumor recurrence was mainly through hematogenous dissemination. According to univariate Cox analysis, the incidence of hematogenous dissemination was $51.2 \%$ in the surgery group and $42.0 \%$ in the surgery plus chemotherapy group, with a significant difference between the two groups $(\mathrm{HR}=0.519,95 \% \mathrm{CI}=0.424-0.826, P=0.002)$ (Table 2). There was no significant difference between the two groups

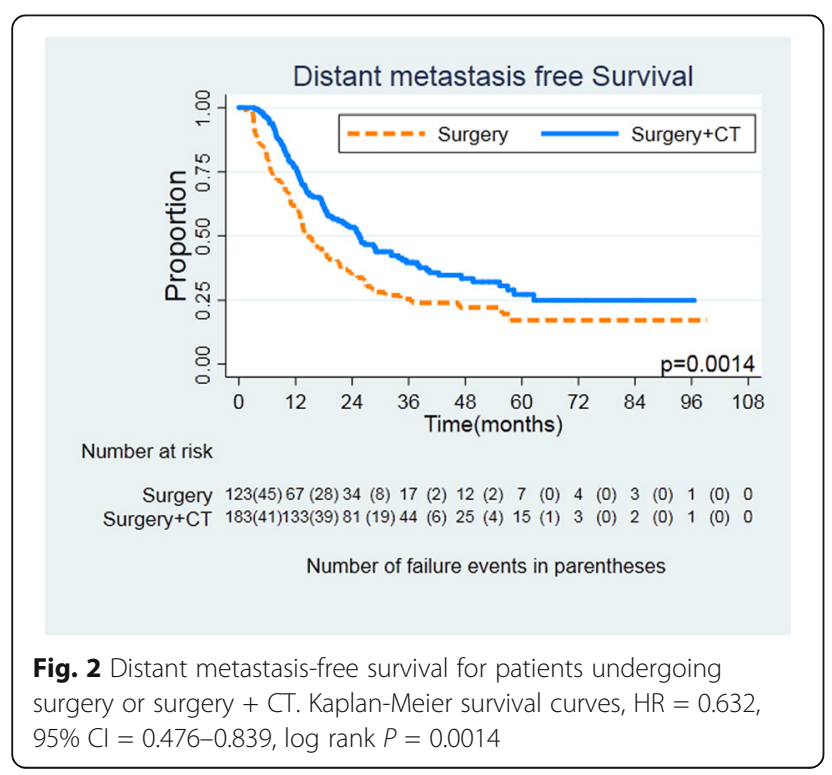

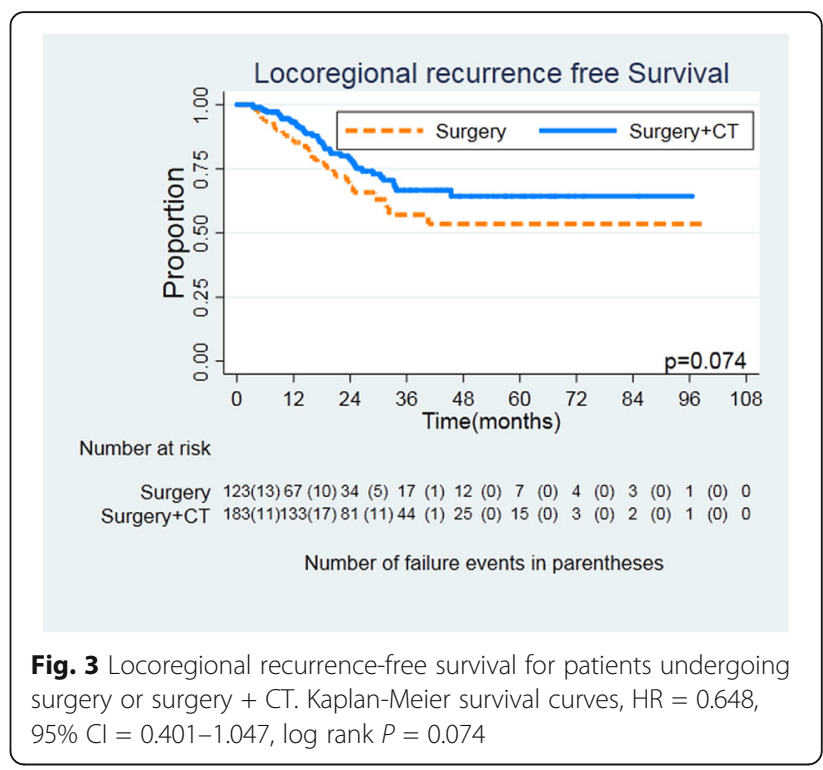

for other recurrence sites: anastomosis, mediastinum, celiac axis, peritoneum, pleura, and nonregional lymph nodes, but the incidence in the surgery plus chemotherapy group was lower than in the surgery group.

\section{Potential prognostic factors for RFS}

Table 3 lists the potential factors affecting the recurrence of AEG patients after surgery. Univariate Cox analysis showed that treatment arm, age, pN stage, and pTNM stage were potential prognostic factors for recurrence. Multivariate Cox analysis using backward step regression analysis showed that $\mathrm{pN}$ stage $(\mathrm{HR}=2.533$, 95\% CI $=1.951-3.289, P<0.001)$ increased the risk of recurrence, while surgery plus chemotherapy $(\mathrm{HR}=$ $0.668,95 \% \mathrm{CI}=0.519-0.861, P=0.02)$ reduced the risk of recurrence. Therefore, according to the multivariate analysis, in stage III AEG patients, $\mathrm{pN}$ stage and surgery alone represented poor prognosis.

\section{Discussion}

Accurate preoperative staging of adenocarcinoma of the esophagogastric junction (AEG) is difficult, especially in lymph node staging. The postoperative treatment plan can be determined according to accurate pathological diagnosis in patients with high recurrence risk. Postoperative adjuvant chemotherapy aims to control potential micrometastasis after surgery and reduce the risk of local recurrence and distant metastasis.

We found that the main sites of local recurrence of AEG were anastomosis and mediastinum in the thoracic cavity $(8.1 \%$ vs $7.6 \%, 5.6 \%$ vs $4.9 \%$, in the surgery and surgery plus chemotherapy groups, respectively). The recurrence rate in lymph nodes around the celiac axis was $9.7 \%$ and $9.2 \%$ in the surgery and surgery plus 
Table 2 Results of univariate Cox regression analysis of RFS time per treatment arm

\begin{tabular}{|c|c|c|c|c|c|}
\hline Site of recurrence & $S(n=123), n(\%)$ & $S+C T(n=183), n(\%)$ & $\mathrm{HR}$ & $95 \% \mathrm{Cl}$ & $P$ value \\
\hline Anastomosis & $10(8.1)$ & $14(7.6)$ & 0.664 & $0.294-1.497$ & 0.323 \\
\hline Mediastinum & $7(5.6)$ & $9(4.9)$ & 0.613 & $0.228-1.650$ & 0.333 \\
\hline Celiac axis & $12(9.7)$ & $17(9.2)$ & 0.615 & $0.290-1.305$ & 0.205 \\
\hline Pleural & $18(14.6)$ & $21(11.4)$ & 0.588 & $0.313-1.105$ & 0.099 \\
\hline Peritoneal & $5(4.0)$ & $7(3.8)$ & 0.712 & $0.226-2.249$ & 0.563 \\
\hline Hematogenous & $63(51.2)$ & $77(42.0)$ & 0.591 & $0.424-0.826$ & 0.002 \\
\hline Nonregional lymph nodes & $9(7.3)$ & $13(7.1)$ & 0.985 & $0.292-1.605$ & 0.383 \\
\hline
\end{tabular}

chemotherapy groups, respectively, suggesting that Siewert II AEG may metastasize both downward and upward, showing bidirectional features. Multicenter studies [13] have shown that proximal gastrectomy, lower esophageal resection, and local lymph node resection are the minimum requirements for surgical treatment of AEG. Expanding esophagectomy and enlarging the scope of lymph node dissection do not improve local recurrence [14]. Other studies [15] have shown that the overall survival is not significantly related to the dissected mediastinal lymph nodes. In our study, there was no difference in the recurrence rate between patients treated with transthoracic or abdominal surgery. However, the local recurrence rate in the surgery group was higher than that in the surgery plus chemotherapy group (23.5\% vs $21.8 \%)$. Although the Kaplan-Meier curve showed no significant difference in local recurrence between the two groups, the survival curve of the surgery plus chemotherapy group was above that of the surgery group, suggesting that the surgery plus chemotherapy had a tendency to reduce local recurrence, and the effect was not significant, which might be related to the surgical injury and blockage of blood vessels and lymph nodes in the surgical area, which to some extent affect inhibition of potential micrometastasis in the surgical area by chemotherapeutic drugs. Currently, neoadjuvant chemotherapy and neoadjuvant radiochemotherapy are the hotspots in the field of cancer research. There is also evidence [16-18] to indicate that neoadjuvant chemotherapy or neoadjuvant radiochemotherapy can reduce local recurrence of AEG and improve prognosis, but there is still controversy about this treatment [19]. Due to the fear of cancer [20] and concern about complications associated with neoadjuvant therapy, neoadjuvant chemotherapy in our medical center is not smoothly administered. Only $2.4 \%$ of our patients received neoadjuvant chemotherapy; therefore, adjuvant treatment after surgery is still valuable in patients.

Patients with AEG have a high risk of hematogenous dissemination after surgery. Liver metastasis can occur as early as 1 month postoperatively. Distant metastasis sites vary, mainly the liver and lungs, with multiple subcutaneous, ovarian, and small intestinal metastases being less common. Compared with surgery alone, surgery plus chemotherapy reduced hematogenous dissemination (51.2\% vs $42.0 \%)$. Distant pleural and peritoneal

Table 3 Univariate and multivariable Cox regression analyses for RFS

\begin{tabular}{|c|c|c|c|c|c|c|}
\hline \multirow[t]{2}{*}{ Factor } & \multicolumn{2}{|c|}{ Recurrence incidence (\%) } & \multicolumn{2}{|l|}{ Univariable } & \multicolumn{2}{|l|}{ Multivariable } \\
\hline & $S$ & $\mathrm{~S}+\mathrm{CT}$ & $\mathrm{HR}(95 \% \mathrm{Cl})$ & $P$ value & $\mathrm{HR}(95 \% \mathrm{Cl})$ & $P$ value \\
\hline Age, years $(\leqq 63 />63)$ & $80.7 / 91.5$ & $74.1 / 81.6$ & $1.451(1.130-1.863)$ & 0.03 & $1.282(0.996-1.651)$ & 0.054 \\
\hline Sex (male/female) & $87.2 / 84.6$ & $77.5 / 74.0$ & $0.890(0.610-1.298)$ & 0.546 & NA & \\
\hline Histology (AC/mucinous AC) & $85.7 / 92.0$ & $76.0 / 80.0$ & $1.072(0.800-1.436)$ & 0.642 & NA & \\
\hline Tumor length, $\mathrm{cm}(\leqq 5.5 />5.5)$ & $88.5 / 84.9$ & $76.8 / 77.2$ & $0.979(0.762-1.257)$ & 0.865 & NA & \\
\hline pT stage (T2, T3/T4a) & 92.9/73.6 & 78.5/75.0 & $0.804(0.618-1.045)$ & 0.103 & NA & \\
\hline pN stage (N0, N1, N2/N3) & $82.4 / 93.8$ & $64.3 / 98.5$ & $2.624(2.021-3.407)$ & $<0.001$ & $2.533(1.951-3.289)$ & $<0.001$ \\
\hline pTNM stage (IIla, IIIb/IIIc) & $84.3 / 89.8$ & $61.1 / 90.8$ & $2.087(1.614-2.698)$ & $<0.001$ & $1.214(0.804-1.833)$ & 0.356 \\
\hline ALI (no/yes) & $87.5 / 85.7$ & $72.5 / 85.7$ & $1.222(0.938-1.592)$ & 0.138 & NA & \\
\hline PNI (no/yes) & $88.7 / 84.6$ & $74.7 / 80.0$ & $1.266(0.984-1.627)$ & 0.067 & NA & \\
\hline Method of resection (TTE/TAE) & $88.5 / 84.9$ & $88.2 / 66.1$ & $0.799(0.614-1.040)$ & 0.096 & NA & \\
\hline Treatment arm $(S / S+C T)$ & 86.9 & 77.0 & $0.637(0.495-0.820)$ & $<0.001$ & $0.668(0.519-0.861)$ & 0.02 \\
\hline Number of resected lymph nodes $(\leqq 19 />19)$ & $87.1 / 77.0$ & $86.8 / 77.1$ & $0.954(0.743-1.224)$ & 0.712 & NA & \\
\hline
\end{tabular}


metastases occurred in some patients via implantation or hematogenous dissemination of cancer cells. But whether implantation of cancer cells occurred during surgery or was caused by long-term hematogenous dissemination is unclear. In univariate Cox analysis, it was found that the ratio of pleural and peritoneal metastases in the surgery plus chemotherapy group was lower than that in the surgery group ( $3.8 \%$ vs $4.0 \%, 11.4 \%$ vs $14.6 \%)$ but these differences were not significant $(P=0.563$, 0.099).

In our study, within 24 months after surgery, most patients had a recurrence $(62.0 \%, 190 / 306): 72.3 \%(89 / 123)$ in the surgery group and $55.1 \%(101 / 183)$ in the surgery plus chemotherapy group, indicating that advanced AEG has high potential of early recurrence. Previous studies have shown that survival rates of patients with tumor recurrence are low, especially in those with earlier recurrence $[21,22]$. Multivariate Cox analysis showed that patients with higher $\mathrm{pN}$ stage were more prone to recurrence. Surgery plus chemotherapy may be beneficial to RFS, but the recurrence rate was still high. Therefore, for AEG patients, we should focus on $\mathrm{pN}$ staging, modify the follow-up protocol within 2 years after surgery, and increase the frequency of follow-up appropriately, so as to find timely evidence of recurrence and formulate subsequent treatment strategies. At the same time, we found an interesting phenomenon in that the age of patients in the surgery plus chemotherapy group was lower than that in the surgery group (median age 62 years vs 65 years, $P<0.001$ ). Univariate Cox analysis showed that older age was associated with recurrence after surgery. This indicated that the younger patients had higher compliance with subsequent treatment, thus improving the prognosis.

This retrospective study had some limitations: although there were inclusion criteria, there may have been selection bias; for example, patients who were lost to follow up may have had no recurrence. Unfortunately, we were unable to obtain sufficient data on follow-up treatment after relapse. This study was conducted in a single center, which helped us to understand the recurrence mode of advanced AEG and improve subsequent treatment strategies. Strengthening health education and improving patient compliance, and increasing the surgical area (including lower mediastinum and upper abdomen) for radiotherapy may also help to reduce local recurrence. However, the ARTIST (Adjuvant Chemoradiation Therapy in Stomach Cancer) trial [23] found that additional postoperative radiotherapy had the same benefit as chemotherapy alone in preventing recurrence of gastric cancer. Therefore, while focusing on randomized clinical trials $[24,25]$, we also need to develop and optimize treatment strategies that accord with the medical conditions of the local area. We found that stage III
AEG mainly metastasizes to distant sites, predominantly through hematogenous transmission. We recommend increasing the number of follow-up visits within 2 years after surgery, especially in the second year. Surgery plus chemotherapy can improve RFS and reduce distant metastasis, but they do not have a beneficial role in controlling local recurrence.

\section{Conclusions}

Patients with AEG have a high risk of hematogenous dissemination after surgery. Postoperative treatment arm and $\mathrm{pN}$ stage were independent risk factors in patients with AEG. Surgery plus chemotherapy may be beneficial to RFS, but the recurrence rate was still high. For AEG patients, we should focus on $\mathrm{pN}$ staging, and the future direction in this field will probably focus on modifying the follow-up protocol after surgery, strengthening health education and improving patient compliance, and increasing the surgical area for radiotherapy.

\section{Abbreviations}

AEG: Adenocarcinoma of the esophagogastric junction; RFS: Recurrence-free survival; S: Surgery; CT: Chemotherapy; HR: Hazard ratio; Cl: Confidence interval; AC: Adenocarcinoma; p: Pathologic; c: Clinical; ALI: Angiolymphatic invasion; PNI: Perineural invasion; TTE: Transthoracic esophagoastrectomy; n: Number; TAE: Transabdominal esophagoastrectomy; NA: Not applicable

\section{Acknowledgements}

Not applicable.

\section{Authors' contributions}

XHT and ZQG built the conception and designed the study. ZLG, MJ, and LS provided statistical analysis and interpretation. $\mathrm{LHJ}$ and JT re-analyzed the data. XHT wrote the manuscript. ZQG reviewed and revised the manuscript. All authors have read and approved the final manuscript.

\section{Funding}

Supported by the Shandong Medical Science and Technology Development Program (No. 2017WS555).

Availability of data and materials

The data used and analyzed in the current study are available from the corresponding author upon reasonable request.

Ethics approval and consent to participate

This study was approved by the Ethics Committee of the Binzhou Medical University Hospital (No. 2018-WST-2017WS555).

Consent for publication

Not applicable.

\section{Competing interests}

The authors declare that there is no conflict of interest related to this study.

\section{Author details}

'Department of Thoracic Surgery, Binzhou Medical University Hospital, No. 661 Huanghe 2nd Road, Binzhou 256603, Shandong, People's Republic of China. ${ }^{2}$ Department of Neonatal Intensive Care Unit, Binzhou People's Hospital, No. 515 Huanghe 7th Road, Binzhou 256603, Shandong, People's Republic of China. 
Received: 24 April 2020 Accepted: 15 June 2020

Published online: 27 June 2020

\section{References}

1. Liu K, Yang K, Zhang W, Chen X, Chen X, Zhang B, Chen Z, Chen J, Zhao Y, Zhou $Z$, et al. Changes of esophagogastric junctional adenocarcinoma and gastroesophageal reflux disease among surgical patients during 1988-2012: a single-institution, high-volume experience in China. Ann Surg. 2016;263: 88-95.

2. Rudiger Siewert J, Feith M, Werner M, Stein HJ. Adenocarcinoma of the esophagogastric junction: results of surgical therapy based on anatomical/ topographic classification in 1,002 consecutive patients. Ann Surg. 2000;232: 353-61.

3. Cao J, Yang T, Wang G, Zhang H, You Y, Chen J, Yang J, Yang W. Analysis of the clinicopathological features and prognostic factors in 734 cases of Chinese Hui and Han patients with adenocarcinoma of the esophagogastric junction. Surg Oncol. 2018;27:556-62.

4. Giacopuzzi S, Bencivenga M, Weindelmayer J, Verlato G, de Manzoni G Western strategy for EGJ carcinoma. Gastric Cancer. 2017;20:60-8.

5. Nobel T, Molena D. Surgical principles for optimal treatment of esophagogastric junction adenocarcinoma. Ann Gastroenterol Surg. 2019;3 390-5.

6. Davies AR, Gossage JA, Zylstra J, Mattsson F, Lagergren J, Maisey N, Smyth EC, Cunningham D, Allum WH, Mason RC. Tumor stage after neoadjuvant chemotherapy determines survival after surgery for adenocarcinoma of the esophagus and esophagogastric junction. J Clin Oncol. 2014:32:2983-90.

7. Al-Batran SE, Goetze TO, Mueller DW, Vogel A, Winkler M, Lorenzen S, Novotny A, Pauligk C, Homann N, Jungbluth T, et al. The RENAISSANCE (AIO-FLOT5) trial: effect of chemotherapy alone vs. chemotherapy followed by surgical resection on survival and quality of life in patients with limitedmetastatic adenocarcinoma of the stomach or esophagogastric junction - a phase III trial of the German AIO/CAO-V/CAOGI. BMC Cancer. 2017:17:893.

8. Fuchs CS, Niedzwiecki D, Mamon HJ, Tepper JE, Ye X, Swanson RS, Enzinger PC, Haller DG, Dragovich T, Alberts SR, et al. Adjuvant chemoradiotherapy with epirubicin, cisplatin, and fluorouracil compared with adjuvant chemoradiotherapy with fluorouracil and leucovorin after curative resection of gastric cancer: results from CALGB 80101 (Alliance). J Clin Oncol. 2017;35: $3671-7$

9. Hosoda K, Yamashita K, Katada N, Watanabe M. Overview of multimodal therapy for adenocarcinoma of the esophagogastric junction. Gen Thorac Cardiovasc Surg. 2015:63:549-56.

10. Maron SB, Chase LM, Lomnicki S, Kochanny S, Moore KL, Joshi SS, Landron S, Johnson J, Kiedrowski LA, Nagy RJ, et al. Circulating tumor DNA sequencing analysis of gastroesophageal adenocarcinoma. Clin Cancer Res. 2019:25:7098-112.

11. Marano L, Boccardi V, Braccio B, Esposito G, Grassia M, Petrillo M, Pezzella M, Porfidia R, Reda G, Romano A, et al. Comparison of the 6th and 7th editions of the AJCC/UICC TNM staging system for gastric cancer focusing on the " $\mathrm{N}$ " parameter-related survival: the monoinstitutional NodUs Italian study. World J Surg Oncol. 2015:13:215

12. Ando N, lizuka T, Ide H, Ishida K, Shinoda M, Nishimaki T, Takiyama W, Watanabe H, Isono K, Aoyama N, et al. Surgery plus chemotherapy compared with surgery alone for localized squamous cell carcinoma of the thoracic esophagus: a Japan Clinical Oncology Group Study--JCOG9204. J Clin Oncol. 2003;21:4592-6.

13. Yoshikawa T, Takeuchi H, Hasegawa S, Nozaki I, Kishi K, Ito S, Ohi M, Mine S, Hara J, Matsuda T, et al. Theoretical therapeutic impact of lymph node dissection on adenocarcinoma and squamous cell carcinoma of the esophagogastric junction. Gastric Cancer. 2016;19:143-9.

14. Hulscher JB, van Sandick JW, de Boer AG, Wijnhoven BP, Tijssen JG, Fockens P, Stalmeier PF, ten Kate FJ, van Dekken $H$, Obertop $H$, et al. Extended transthoracic resection compared with limited transhiatal resection for adenocarcinoma of the esophagus. N Engl J Med. 2002;347:1662-9.

15. Yabusaki H, Nashimoto A, Matsuki A, Aizawa M. Comparison of the surgical treatment strategies for Siewert type II squamous cell carcinoma in the same area as esophagogastric junction carcinoma: data from a single Japanese high-volume cancer center. Surg Today. 2014:44:1522-8.

16. Anderegg MCJ, van der Sluis PC, Ruurda JP, Gisbertz SS, Hulshof M, van Vulpen M, Mohammed NH, van Laarhoven HWM, Wiezer MJ, Los $\mathrm{M}$, et al. Preoperative chemoradiotherapy versus perioperative chemotherapy for patients with resectable esophageal or gastroesophageal junction adenocarcinoma. Ann Surg Oncol. 2017:24:2282-90.

17. Zhao X, Ren Y, Hu Y, Cui N, Wang X, Cui Y. Neoadjuvant chemotherapy versus neoadjuvant chemoradiotherapy for cancer of the esophagus or the gastroesophageal junction: a meta-analysis based on clinical trials. PLoS One. 2018;13:e0202185

18. Shapiro J, van Lanschot JJB, Hulshof M, van Hagen P, van Berge Henegouwen MI, Wijnhoven BPL, van Laarhoven HWM, Nieuwenhuijzen GAP, Hospers GAP, Bonenkamp JJ, et al. Neoadjuvant chemoradiotherapy plus surgery versus surgery alone for oesophageal or junctional cancer (CROSS): long-term results of a randomised controlled trial. Lancet Oncol. 2015;16:1090-8

19. Reddavid R, Sofia S, Chiaro P, Colli F, Trapani R, Esposito L, Solej M, Degiuli M. Neoadjuvant chemotherapy for gastric cancer. Is it a must or a fake? World J Gastroenterol. 2018:24:274-89.

20. Simonelli LE, Siegel SD, Duffy NM. Fear of cancer recurrence: a theoretical review and its relevance for clinical presentation and management. Psychooncology. 2017;26:1444-54.

21. Eom BW, Yoon H, Ryu KW, Lee JH, Cho SJ, Lee JY, Kim CG, Choi IJ, Lee JS, Kook MC, et al. Predictors of timing and patterns of recurrence after curative resection for gastric cancer. Dig Surg. 2010;27:481-6.

22. Kang WM, Meng QB, Yu JC, Ma ZQ, Li ZT. Factors associated with early recurrence after curative surgery for gastric cancer. World I Gastroenterol. 2015:21:5934-40.

23. Park SH, Sohn TS, Lee J, Lim DH, Hong ME, Kim KM, Sohn I, Jung SH, Choi $M G$, Lee JH, et al. Phase III trial to compare adjuvant chemotherapy with capecitabine and cisplatin versus concurrent chemoradiotherapy in gastric cancer: final report of the adjuvant chemoradiotherapy in stomach tumors trial, including survival and subset analyses. J Clin Oncol. 2015;33:3130-6.

24. Noordman BJ, Verdam MGE, Lagarde SM, Shapiro J, Hulshof M, van Berge Henegouwen MI, Wijnhoven BPL, Nieuwenhuijzen GAP, Bonenkamp JJ, Cuesta MA, et al. Impact of neoadjuvant chemoradiotherapy on healthrelated quality of life in long-term survivors of esophageal or junctional cancer: results from the randomized CROSS trial. Ann Oncol. 2018;29:445-51.

25. Al-Batran SE, Homann N, Pauligk C, Goetze TO, Meiler J, Kasper S, Kopp HG, Mayer F, Haag GM, Luley K, et al: Perioperative chemotherapy with fluorouracil plus leucovorin, oxaliplatin, and docetaxel versus fluorouracil or capecitabine plus cisplatin and epirubicin for locally advanced, resectable gastric or gastro-oesophageal junction adenocarcinoma (FLOT4): a randomised, phase 2/3 trial. Lancet 2019.

\section{Publisher's Note}

Springer Nature remains neutral with regard to jurisdictional claims in published maps and institutional affiliations.

Ready to submit your research? Choose BMC and benefit from:

- fast, convenient online submission

- thorough peer review by experienced researchers in your field

- rapid publication on acceptance

- support for research data, including large and complex data types

- gold Open Access which fosters wider collaboration and increased citations

- maximum visibility for your research: over $100 \mathrm{M}$ website views per year

At BMC, research is always in progress.

Learn more biomedcentral.com/submissions 